\title{
RESEARCH
}

Open Access

\section{Apolipoproteins $A 1$ and $B$ and their ratio in acute ischemic stroke patients with intracranial and extracranial arterial stenosis: an Egyptian study}

Ebtesam Mohammed Fahmy ${ }^{1}$, Mohammed Ahmed El Sayed El Awady', Sahar Abdel-Atty Sharaf², Nora Mahmoud Selim², Hazem El Sawy Abdo ${ }^{1}$ and Shaimaa Shaheen Mohammed ${ }^{1 *}$ (i)

\begin{abstract}
Background: Apolipoprotein A1 and B and their ratio are considered a better biomarker for cardiovascular diseases than a lipid profile, but this previous finding is not proved to cerebrovascular ischemic diseases. The aim of this study is to assess the relation between apolipoprotien A1 and B and their ratio to intra- and extracranial carotid atherosclerosis in patients with ischemic acute stroke.

Methods: 90 Egyptian patients with acute ischemic stroke are included in the study, and they have been classified into 3 groups: group 1 includes 30 patients with intracranial stenosis, group 2 includes 30 patients with extracranial arterial stenosis, and group 3 includes 30 patients with non-arterial stenosis. Patients were subjected to clinical assessment, routine laboratory measures, and Color-Coded Duplex Sonography for extracranial and intracranial arteries. The measurement of serum levels of apolipoproteins A1 and B was done using enzyme-linked immunosorbent assay (ELISA).

Results: A statistically significant difference was found between patient groups as regards the frequency of abnormal serum LDL-cholesterol $(p=0.04)$, being elevated in patients with extracranial stenosis $(p=0.01)$. There was a significant difference between patients groups as regards the frequency of abnormal serum HDL-cholesterol $(p=0.02)$, being lower in patients with extracranial stenosis. High Apo B/A1 ratio was an independent risk factor for intracranial arterial stenosis $(p=0.045)$. An abnormal elevation of serum LDL cholesterol was an independent risk factor of extracranial arterial stenosis $(p=0.021)$.

Conclusion: Apo B/A1 ratio is an independent risk factor for intracranial arterial stenosis, while serum LDL cholesterol is an independent risk factor for extracranial arterial stenosis. Apo B/A1 ratio and serum LDL cholesterol are reliable serum biomarkers for cranial arterial stenosis in acute ischemic stroke patients.
\end{abstract}

Keywords: Apolipoprotein A1, Apolipoprotein B, Atherosclerosis, Intracranial stenosis, Extracranial stenosis

\footnotetext{
* Correspondence: shaheen.shaimaa@yahoo.com

${ }^{1}$ Neurology Department, Faculty of Medicine, Cairo University, Cairo, Egypt

Full list of author information is available at the end of the article
}

\section{Springer Open}

(c) The Author(s). 2020 Open Access This article is licensed under a Creative Commons Attribution 4.0 International License, which permits use, sharing, adaptation, distribution and reproduction in any medium or format, as long as you give appropriate credit to the original author(s) and the source, provide a link to the Creative Commons licence, and indicate if changes were made. The images or other third party material in this article are included in the article's Creative Commons licence, unless indicated otherwise in a credit line to the material. If material is not included in the article's Creative Commons licence and your intended use is not permitted by statutory regulation or exceeds the permitted use, you will need to obtain permission directly from the copyright holder. To view a copy of this licence, visit http://creativecommons.org/licenses/by/4.0/. 


\section{Introduction}

Cerebral artery stenosis is known as a primary cause of stroke. It can be divided into intracranial arterial stenosis (ICAS), extracranial arterial stenosis (ECAS), and combined intracranial and extracranial arterial stenosis. Intracranial arterial stenosis causes approximately 8 to $12 \%$ of ischemic stroke. The most prevalent type of extracranial arterial stenosis is carotid artery stenosis; it represents about $15 \%$ of ischemic stroke [1].

The distribution of carotid artery stenosis was different among races. It was known that intracranial carotid artery stenosis is more common in the African-American and Asian population while extracranial stenosis is more predominant in Caucasians. Meticulous studies were done to detect the racial difference as a risk of stroke, and now, it is found that intracranial stenosis is a risk factor for stroke in Caucasian which is a different finding than that was reported previously [2]. In Egypt, the ICAD is more prevalent than ECAD as $67 \%$ has intracranial artery stenosis and $27 \%$ has asymptomatic intracranial carotid artery stenosis in a study done by Moustafa and colleagues in Egyptian patients with acute ischemic stroke within 2 days of onset [3].

The natural history of intracranial carotid atherosclerotic disease (ICAD) was well-established in the WarfarinAspirin Symptomatic Intracranial Disease Trial (WASID), which detects that severe stenosis $>70 \%$ leads to a higher incidence of stroke that is about )19\%( in the territory of the symptomatic stenotic artery despite antiplatelet management if it compared to lower incidence of stroke (8\%) in patients with stenosis $<70 \%$ [4].

Few studies were done to evaluate the risk for intracranial carotid stenosis which may be related to the poverty of non-invasive technics that can visualize the intracranial carotid artery. Nowadays, many non-invasive imaging techniques were developed like trans-cranial Doppler ultrasonography (TCD), magnetic resonance angiography (MRA), and computed tomography angiography (CTA) [5].

Apolipoproteins A1 and B are structural proteins for lipoproteins, and it is considered a better predictor for stroke than the ordinary lipid profile. Apolipoprotein A1is a structural protein for high-density lipoprotein (HDL), which transfers cholesterol from the peripheral tissue to the liver for final excretion (it has an antiatherogenic effect). Apolipoprotein B is a structural protein for very low- low-density lipoprotein (VLDL, LDL), and it transfers the lipid from the liver to the gut and other tissues for peripheral utilization (atherogenic effect). Apo $\mathrm{B} / \mathrm{A} 1$ ratio which is the ratio between atherogenic to anti-atherogenic particles is a better predictor for risk of coronary vascular disease than the known ordinary lipid and lipoprotein profile [6-8].

Few studies were done to detect the relation between apolipoproteins and carotid atherosclerosis by its subtypes intracranial and extracranial. This study was conducted to investigate the relation of apolipoproteins A1 and B, and their ratio to intracranial and extracranial atherosclerotic arterial stenosis in a sample of Egyptian patients with acute ischemic stroke.

\section{Methods}

This is a cross-sectional study enrolled 90 Egyptian stroke patients, in the period from January 2018 to April 2019. Patients were collected within 7 days from the onset of acute ischemic stroke. The aim and procedures of the study were explained to all patients, and informed oral consents were taken prior to participation to ensure complete satisfaction.

Inclusion criteria were patients (of both sexes) presented with acute ischemic cerebral infarction within 7 days from the onset, age above 45 years, and stable and fully conscious patients. Exclusion criteria were cardio-embolic diseases (as atrial fibrillation, rheumatic heart disease, artificial valve, intracardiac thrombus or tumor, cardiomyopathy, myocardial infarction within 3 months), severe liver or renal insufficiency, stroke caused by non-atherosclerotic vascular stenosis, and intake of lipid-modifying therapy.

Patients were classified into three groups: group 1 included 30 patients with intracranial arterial stenosis, group 2 included 30 patients with extracranial arterial stenosis, and group 3 included 30 patients without arterial stenosis.

Patients were submitted to full general and neurological examination. The initial severity of stroke was measured by the National Institutes of Health Stroke Scale (NIHSS) [7]. Non-contrast brain computed tomography (CT) (computed tomography, Toshiba, Aquilion; 64 slices, Japan, 2005) and/or magnetic resonance imaging (MRI) (magnetic resonance imaging, Philips, Achiva and Intera; 1.5 Tesla, Holland, 2003) to confirm the diagnosis of acute ischemic stroke.

Color-coded Duplex sonography for intracranial and extracranial arteries has done using (Philips iU22 machine, Bothell, WA, USA, 2008). The patients lie down in the supine or semi-supine position with the head slightly hyperextended and rotated $45^{\circ}$ away from the side being examined. A high-frequency (7 to $10 \mathrm{MHz}$ ) linear array transducer was employed to scan the carotid from the most proximal common carotid artery (CCA) to the internal carotid artery (ICA) as far as the mandible permitted. Peak systolic velocities (PSVs) were measured in the common and internal carotid arteries, and when stenosis was detected, the velocities were measured at the maximal stenotic area. The intracranial arteries were evaluated using $2 \mathrm{MHz}$ phased array transducer. Each insonated artery was investigated by peak systolic velocity (PSV) used for the presence of stenosis or occlusion, flow direction (ante-grade or reversed) $[9,10]$. 
Routine laboratory investigations including complete blood count, international neutralization rate, partial thromboplastin time, kidney functions, liver functions, fasting, 2H PP blood sugar, and lipid profile. Dyslipidemia was defined as fasting serum total cholesterol of $\geq$ $200 \mathrm{mg} / \mathrm{dl}$, LDL cholesterol of $\geq 130 \mathrm{mg} / \mathrm{dl}$, and HDL cholesterol of $\leq 40 \mathrm{mg} / \mathrm{dl}$ for men and $\leq 50 \mathrm{mg} / \mathrm{dl}$ for women or a triglyceride concentration of $\geq 150 \mathrm{mg} / \mathrm{dl} \mathrm{[11].}$

Measurement of serum levels of apolipoproteins B and A1 and their ratio: the assay of apolipoproteins B and A1 levels was done for all patients using enzyme-linked immuno-sorbent assay (ELISA) technique. Venous blood samples were collected then centrifuged to get serum. The human apolipoproteins B and A1 kits were used for the quantitative measurement of levels of apolipoproteins B and A1 in serum using the competitive immunoassay technique. Detection range of the kit was $16 \mathrm{ng} /$ $\mathrm{ml}-1000 \mathrm{ng} / \mathrm{ml}$ for Apo B and $1.2 \mathrm{ng} / \mathrm{ml}-80 \mathrm{ng} / \mathrm{ml}$ for Apo A1.

In conditions at which there was a problem in the assay like giving an error as the assay range is not within the detection range of the kit, dilution of the sample done, and then reassessment done. The value of reassessment is then multiplied by the percent of diluting fluid used giving us the actual level which is higher than the detection range [12].

\section{Statistical analysis}

Data were coded and entered using the statistical package for the Social Sciences (SPSS) version 25 (IBM Corp., Armonk, NY, USA). Data was summarized using the mean and standard deviation for quantitative variables and frequencies and relative frequencies for categorical variables. Comparisons between groups were done using unpaired $t$ test or analysis of variance (ANOVA) with multiple comparisons post hoc test in normally distributed quantitative variables while nonparametric Kruskal-Wallis test and Mann-Whitney test were used for non-normally distributed quantitative variables. Logistic regression was done to detect independent predictors for intracranial and extracranial arterial stenosis $[13,14]$.

\section{Results}

\section{Demographic data}

Group I included 15 female (50\%) and 15 male patients (50\%). Their age ranged from 45 to 80 years with a mean of $57.70 \pm 10.81$ years. Group II included 15 female (50\%) and 15 male patients (50\%). Their age ranged from 49 to 78 years with a mean of $62.53 \pm 8.25$ years. Group III included 12 female (40\%) and 18 male patients (60\%). Their age ranged from 45 to 84 years with a mean of $60.40 \pm 10.37$ years. There was no statistically significant difference between the three groups as regards the mean age and sex distribution $(\mathrm{p}=0.17,0.67$, respectively).

\section{Clinical characteristics of patients}

NIHSS scores ranged from 2 to 20 in group I, from 2 to 23 in group II, and from 2 to 23 in group III, with no significant difference between the three groups $(p=$ $0.10)$. Frequency of hypertension, diabetes mellitus, and current smoking are shown in Table 1.

Serum apolipoprotein B ranged from 679 to $1472 \mathrm{ng} /$ $\mathrm{ml}$ with a mean of $1035.07 \pm 246.37 \mathrm{ng} / \mathrm{ml}$ in group $\mathrm{I}$, from 386 to $1602 \mathrm{ng} / \mathrm{ml}$ with a mean of $1048.70 \pm$ $282.16 \mathrm{ng} / \mathrm{ml}$ in group II and from 440 to $1275 \mathrm{ng} / \mathrm{ml}$ with a mean of $943.90 \pm 206.42 \mathrm{ng} / \mathrm{ml}$ in group III.

Serum apolipoproteins A1 ranged from 21.5 to 87.5 $\mathrm{ng} / \mathrm{ml}$ with a mean value of $47.78 \pm 14.97 \mathrm{ng} / \mathrm{ml}$ in group I, from 25 to $130 \mathrm{ng} / \mathrm{ml}$ with a mean of $49.68 \pm$ $20.29 \mathrm{ng} / \mathrm{ml}$ in group II and from 35 to $130 \mathrm{ng} / \mathrm{ml}$ with a mean of $51.32 \pm 18.83 \mathrm{ng} / \mathrm{ml}$ in group III.

Apo B/A1 ratio ranged from 14.1 to 31.7 with a mean of $22.64 \pm 4.64$ in group I, from 11.30 to 36.40 with a mean of $22.48 \pm 5.72$ in group II, and from 9.4 to 28.9 with a mean of $19.86 \pm 5.49$ in group III. There was a statistically significant difference between patients groups as regards the frequency of abnormal serum LDL cholesterol $(p=0.04)$. Moreover, there was insignificant difference between the three groups as regards the frequency of abnormal serum HDL cholesterol $(p=0.07)$. No significant difference was found as regards total serum cholesterol $(p=0.1)$ or triglycerides $(p=0.5)$ (Table 2, Fig. 1).

Total serum cholesterol ranged from 118 to $294 \mathrm{mg} / \mathrm{dl}$ with a mean $196.40 \pm 48.78 \mathrm{mg} / \mathrm{dl}$ in group I, from 87 to $283 \mathrm{mg} / \mathrm{dl}$ with a mean $196 \pm 58.62 \mathrm{mg} / \mathrm{dl}$ in group II, and from 71 to $335 \mathrm{mg} / \mathrm{dl}$ with a mean $185.90 \pm 54.56$ $\mathrm{mg} / \mathrm{dl}$ in group III. Elevated total serum cholesterol was found in 14 patients (46.7\%) of group I, 15 patients (50\%) of group II, and 8 patients $(26.7 \%)$ of group III (Table 2).

Serum LDL cholesterol ranged from 28 to $222 \mathrm{mg} / \mathrm{dl}$ with a mean $123.50 \pm 45.64 \mathrm{mg} / \mathrm{dl}$ in group I, from 38 to

Table 1 Frequency of hypertension, diabetes, and smoking among patients groups

\begin{tabular}{|c|c|c|c|c|c|c|c|c|}
\hline & & \multicolumn{2}{|c|}{ Group I } & \multicolumn{2}{|c|}{ Group II } & \multicolumn{2}{|c|}{ Group III } & \multirow[t]{2}{*}{$P$ value } \\
\hline & & Count & $\%$ & Count & $\%$ & Count & $\%$ & \\
\hline \multirow[t]{2}{*}{ Hypertension } & Yes & 23 & 76.7 & 22 & 73.3 & 21 & 70 & 0.8 \\
\hline & No & 7 & 23.3 & 8 & 26.7 & 9 & 30 & \\
\hline \multirow[t]{2}{*}{ Diabetes } & Yes & 16 & 53.3 & 16 & 53.3 & 11 & 36.7 & 0.3 \\
\hline & No & 14 & 46.7 & 14 & 46.7 & 19 & 63.3 & \\
\hline \multirow[t]{2}{*}{ Smoking } & Yes & 10 & 33.3 & 15 & 50 & 13 & 43.3 & 0.4 \\
\hline & No & 20 & 66.7 & 15 & 50 & 17 & 56.7 & \\
\hline
\end{tabular}


Table 2 Comparison of frequency of abnormal lipid profile between patients groups

\begin{tabular}{|c|c|c|c|c|c|c|c|c|}
\hline \multirow[t]{2}{*}{ Serum lipids } & & \multicolumn{2}{|c|}{ Group I (intracranial stenosis) } & \multicolumn{2}{|c|}{ Group II (extracranial stenosis) } & \multicolumn{2}{|c|}{ Group III (no stenosis) } & \multirow[t]{2}{*}{$P$ value } \\
\hline & & Count & $\%$ & Count & $\%$ & Count & $\%$ & \\
\hline \multirow[t]{2}{*}{ Cholesterol (mg/dl) } & Normal & 16 & 53.3 & 15 & 50 & 22 & 73.3 & 0.1 \\
\hline & Abnormal & 14 & 46.7 & 15 & 50 & 8 & 26.7 & \\
\hline \multirow[t]{2}{*}{ LDL-cholesterol (mg/dl) } & Normal & 15 & 50 & 13 & 43.3 & 22 & 73.3 & $0.04^{*}$ \\
\hline & Abnormal & 15 & 50 & 17 & 56.7 & 8 & 26.7 & \\
\hline \multirow[t]{2}{*}{ HDL-cholesterol (mg/dl) } & Normal & 9 & 30 & 5 & 16.7 & 13 & 43.3 & 0.07 \\
\hline & Abnormal & 21 & 70 & 25 & 83.3 & 17 & 56.7 & \\
\hline \multirow[t]{2}{*}{ Triglycerides (mg/dl) } & Normal & 18 & 60 & 19 & 63.3 & 22 & 73.3 & 0.5 \\
\hline & Abnormal & 12 & 40 & 11 & 36.7 & 8 & 26.7 & \\
\hline
\end{tabular}

*Significant

$197 \mathrm{mg} / \mathrm{dl}$ with a mean $119.13 \pm 42.99 \mathrm{mg} / \mathrm{dl}$ in group II, and from 38 to $223 \mathrm{mg} / \mathrm{dl}$ with a mean $118.03 \pm 37.52$ $\mathrm{mg} / \mathrm{dl}$ in group III. Elevated serum LDL cholesterol was found in 15 patients (50\%) of group I, 17 patients (56.7\%) of group II, and 8 patients (26.7\%) of group III (Table 2).

Serum HDL cholesterol ranged from 23 to $60 \mathrm{mg} / \mathrm{dl}$ with a mean $39.93 \pm 9.06 \mathrm{mg} / \mathrm{dl}$ in group I, from 26 to $60 \mathrm{mg} / \mathrm{dl}$ with a mean $37.30 \pm 8.54 \mathrm{mg} / \mathrm{dl}$ in group II, and from 16 to $62 \mathrm{mg} / \mathrm{dl}$ with a mean $40.53 \pm 12.48 \mathrm{mg} /$ $\mathrm{dl}$ in group III. Low serum HDL cholesterol was found in 21 patients $(70 \%)$ of group I, 25 patients $(83.3 \%)$ of group II, and 17 patients (56.7\%) of group III (Table 2).

Serum triglycerides ranged from 57 to $429 \mathrm{mg} / \mathrm{dl}$ with a mean $169.23 \pm 98.31 \mathrm{mg} / \mathrm{dl}$ in group I, from 39 to $324 \mathrm{mg} / \mathrm{dl}$ with a mean $133.20 \pm 68.11 \mathrm{mg} / \mathrm{dl}$ in group II, and from 36 to $392 \mathrm{mg} / \mathrm{dl}$ with a mean 137.67 $\pm 79.46 \mathrm{mg} / \mathrm{dl}$ in group III. Elevated serum triglycerides were found in 20 patients (66.7\%) of group I, 15 patients (50\%) of group II, and 17 patients (56.7\%) of group III (Table 2).
There was a statistically significant difference between patients with extracranial stenosis and no stenosis as regards the frequency of abnormal serum LDL cholesterol $(p=0.01)$ and serum HDL-cholesterol $(p=0.02)$, as serum LDL cholesterol was higher, and serum HDL cholesterol was lower in patients with extracranial stenosis. A statistically insignificant difference in serum LDL cholesterol was found between patients with intracranial stenosis and nostenosis group $(p=0.06)$, as abnormal elevation of serum LDL cholesterol was encountered more in the intracranial stenosis group. There was no statistically significant difference between patients with intracranial stenosis and extracranial stenosis as regards the serum LDL cholesterol $(p=0.6)$ or HDL cholesterol $(p=0.2)$.

There was no statistically significant difference between patients with intracranial stenosis, extracranial stenosis, and no-arterial stenosis as regards the mean serum apolipoprotein B $(p=0.2)$ or apo-lipoprotein A1 $(p=0.7)$. There is an insignificant difference in Apo B/ A1 ratio between patients groups $(p=0.07)$ (Table 3).

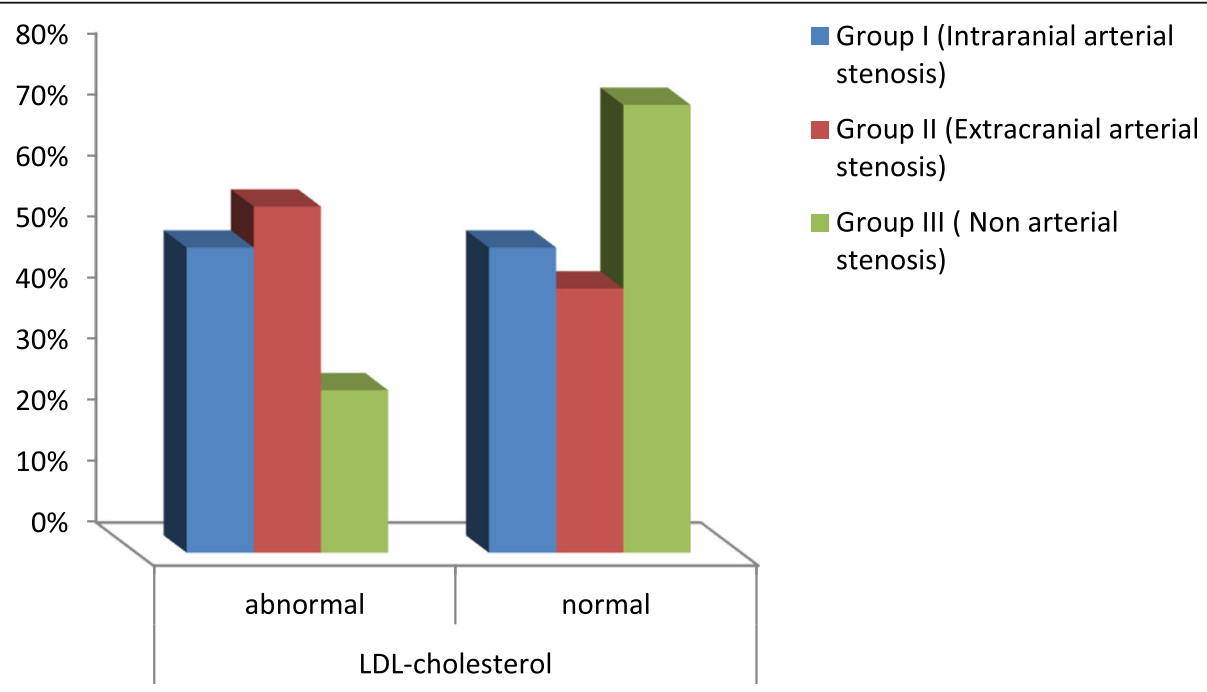

Fig. 1 Comparison of serum LDL cholesterol between groups I, II, and III 
Table 3 Comparison of mean serum levels of apolipoproteins B, A1, and their ratio between patients groups

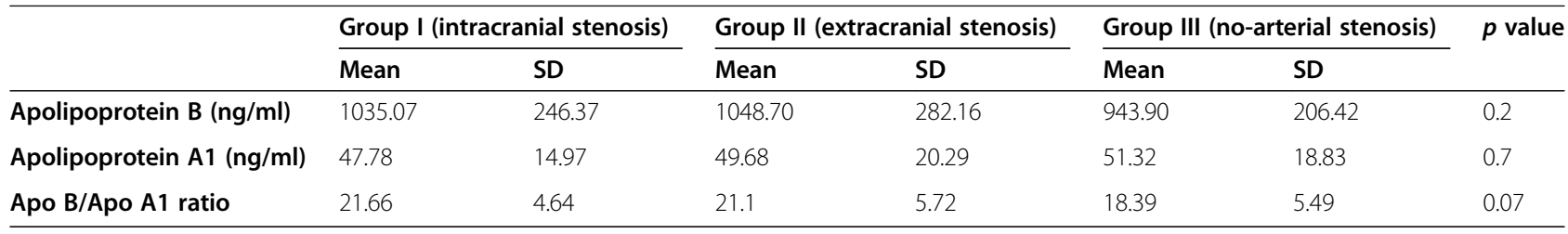

No significant correlation was found between serum apolipoprotein B, apolipoprotein A1 and LDL cholesterol, and HDL cholesterol in groups I, II, or III $(p>$ 0.05). Multivariate logistic regression analysis revealed that high Apo B/A1 ratio is an independent risk factor for intracranial arterial stenosis $(p=0.04)$, and abnormal serum LDL cholesterol is an independent risk factor for extracranial arterial stenosis $(p=0.02)$, see Tables 4 and 5 .

\section{Discussion}

High-lipid profile is associated with atherosclerosis in general but whether a particular lipid profile is associated with extra- and/or intracranial carotid artery stenosis are not well studied [15]. In the present study, we try to find a relation between different lipid parameters and degree of intra- and/or extracranial carotid stenosis in a sample of Egyptian patients presented by acute stroke.

The present study showed a statistically significant difference between extracranial atherosclerotic arterial stenosis and non-arterial stenosis regarding serum LDL cholesterol, and patients with extracranial arterial stenosis had the higher frequency of abnormal LDL cholesterol (high LDL-C). Also, in the present study, abnormal serum LDL cholesterol (high LDL-C) found to be an independent risk factor for extracranial atherosclerotic arterial stenosis, a finding which was in agreement with several previous studies $[16,17]$.

The current study showed a statistically significant difference between extracranial atherosclerotic arterial stenosis and non-arterial stenosis regarding serum HDL cholesterol with patients with extracranial arterial stenosis had the higher frequency of abnormal HDL cholesterol (low HDL-C). This goes in agreement with Kim and collegues and Junyent and collegues [18, 19]. On the contrary, other studies Lei and colleagues and Qian and colleagues, who found that low HDL level was

Table 4 Multivariate logistic regression analysis model of independent factors for intracranial arterial stenosis

\begin{tabular}{|c|c|c|c|c|c|}
\hline & & \multirow[t]{2}{*}{$P$ value } & \multirow[t]{2}{*}{ OR } & \multicolumn{2}{|c|}{ 95\% C.I. } \\
\hline & & & & Lower & Upper \\
\hline $\begin{array}{l}\text { Intracranial } \\
\text { arterial } \\
\text { stenosis }\end{array}$ & $\begin{array}{l}\text { Apo B/Apo } \\
\text { A1 ratio }\end{array}$ & $0.045^{*}$ & 1.118 & 1.002 & 1.246 \\
\hline
\end{tabular}

OR odds ratio, ${ }^{*}$ significant, $\mathrm{Cl}$ confidence interval associated with intracranial stenosis, and this may be explained by ethnic variations $[15,20]$.

The current study revealed no statistical difference between extracranial arterial stenosis, intracranial arterial stenosis, and non-arterial stenosis as regards the frequency of clinical risk factors: hypertension, diabetes, or smoking. This goes in agreement with Kim and colleagues, El Zayat and colleagues and Yang and colleagues [18, 21, 22] who found that the location of cerebral atherosclerosis in extracranial or intracranial arteries is not explained by differences in the known modifiable risk factors among the same ethnic group. It means that modifiable risk factors (diabetes, hypertension, and smoking) have equivalent role in pathogenesis of intracranial and extracranial atherosclerosis.

There was a comprehensive meta-analysis study done by Ding and colleagues [23], on Asian population, investigated the effect of risk factors including age, sex, hypertension, diabetes, dyslipidemia, smoking, and metabolic syndrome (Met.S) on the location of atherosclerotic stenosis like ICAS and ECAS. This meta-analysis revealed that female sex and MetS were more linked to ICAS, while smoking and hyperlipidemia were more linked to ECAS. There was no significant difference between ICAS and ECAS in terms of age, hypertension, and diabetes. The difference between our study and other studies can be explained in terms of sample size and ethnic variations.

In the present study, Apo B/A1 ratio was an independent risk factor for intracranial atherosclerotic arterial stenosis compared to extracranial atherosclerotic arterial stenosis and non-arterial stenosis, a finding which was in agreement with several previous studies. Two Korean studies done by park and colleagues, [24, 25] who found that a higher Apo/A1 ratio is a prognostic factor for ICAS rather than extracranial atherosclerotic stenosis or no cerebral atherosclerotic stenosis and Apo B/A1 ratio

Table 5 Multivariate logistic regression analysis model of independent factors of intracranial arterial stenosis

\begin{tabular}{llllll}
\hline & P value & OR & \multicolumn{2}{l}{$\mathbf{9 5 \%}$ C.I. } \\
\cline { 4 - 6 } & & & Lower & Upper \\
\hline $\begin{array}{l}\text { Extracranial } \\
\begin{array}{l}\text { arterial } \\
\text { stenosis }\end{array}\end{array}$ & $\begin{array}{l}\text { Abnormal } \\
\text { LDL-cholesterol }\end{array}$ & $\mathbf{0 . 0 2 1 *}$ & 3.596 & 1.216 & 10.638 \\
\hline OR odds ratio, *significant & & & & \\
\hline
\end{tabular}


might be a marker for ICAS in Asian patients with stroke. Kim and colleagues [26] also found that low Apo $\mathrm{B} / \mathrm{A} 1$ ratio is associated with stability of angiographic symptomatic intracranial atherosclerotic stenosis.

There were other studies showed that Apo B/A1 ratio is associated with extracranial not intracranial stenosis $[27,28]$. The absence of correlation between Apo B/A1 ratio and LDL-C or HDL-C can be explained by that HDL, and LDL not accurately reflects the concentration of the circulating lipoproteins as these molecules exposed to changes in their size and composition so sometimes lack of correlation between Apo B/A1 ratio and LDL-C or HDL-C could be found [29]. These contradictory findings may be related to differences in study design or ethnic variation as atherosclerosis is a multifactorial disorder with environmental, demographic, and genetic factors leads to its development.

Our study has some limitations. First is the small sample size. Second, its design was cross-sectional, so we could not directly assess the prognostic impact of different lipid profiles and cerebrovascular risk factors in patients with symptomatic intracranial and/or extracranial atherosclerosis. Third, our study population was hospital based, so it may not accurately reflect what happens in the general population. Therefore, revealed results are clearly exploratory and preliminary. Equal sex distribution in the three groups also adds limitation to the study as sex distribution among patients with extracranial and intracranial stenosis.

With the previous limitations, the current study revealed that Apo B/A1 ratio and serum LDL cholesterol can be used as reliable biomarkers for ICAS and ECAS, respectively. Future research including a larger sample size is warranted for further clarification of the relation between apolipoproteins A1, B, and their ratio to intracranial and extracranial atherosclerotic arterial stenosis in patients with acute ischemic stroke.

\section{Conclusion}

From the present study, it is concluded that Apo B/A1 ratio is an independent risk factor for intracranial arterial stenosis, while serum LDL cholesterol is an independent risk factor for extracranial arterial stenosis. Apo B/ A1 ratio and serum LDL cholesterol are reliable serum biomarkers for cranial arterial stenosis in acute ischemic stroke patients.

\footnotetext{
Abbreviations

ELISA: Enzyme-linked immuno-sorbent assay; Apo A1: Apolipoprotein A1; Apo B: Apolipoprotein B; Apo B/A1 ratio: Apolipoprotein B/A1 ratio; ICAS: Intracranial arterial stenosis; ECAS: Extracranial arterial stenosis; WASI D: Warfarin-Aspirin Symptomatic Intracranial Disease Trial; TCD: Trans-cranial Doppler ultrasonography; MRA: Magnetic resonance angiography; MRI: Magnetic resonance imaging; CTA: Computed tomography angiography; CT: Computed tomography; VLDL: Very low-density lipoprotein; LDL: Low-density lipoprotein; LDL-C: Low-density lipoprotein-cholesterol;
}

HDL: High-density lipoprotein; HDL-C: High-density lipoprotein-cholesterol; CCA: Common carotid artery; ICA: Internal carotid artery; PSVs: Peak systolic velocities; Met.S: Metabolic syndrome

\section{Acknowledgements}

Not applicable.

\section{Authors' contributions}

We confirm that E. M contributed to the conception and design of the study. M. A contributed to the conception and design of the study. S. A shared in the analysis and interpretation of the laboratory data. N. M shared in the analysis and interpretation of laboratory data. $\mathrm{H}$. E help in the acquisition of the data and drafting the article. S. S helped in the acquisition of data and drafting the article. The authors have read and approved the manuscript.

\section{Funding}

No funding received.

\section{Availability of data and materials}

The datasets generated and/or analyzed during the current study are not publicly available due to the current Cairo University regulations and Egyptian legislation but are available from the corresponding author on reasonable request and after institutional approval.

\section{Ethics approval and consent to participate}

This study was approved by the ethical committee of the Neurology Department, Faculty of Medicine, Cairo University, in January 2018. No available number. A written consent to participate was taken from patients sharing in this study.

\section{Consent for publication}

Not applicable.

\section{Competing interests}

The authors declare that they have no competing interests.

\section{Author details}

${ }^{1}$ Neurology Department, Faculty of Medicine, Cairo University, Cairo, Egypt. ${ }^{2}$ Clinical pathology Department, Faculty of Medicine, Cairo University, Cairo, Egypt.

Received: 22 July 2020 Accepted: 13 November 2020

Published online: 09 December 2020

\section{References}

1. Wang Y, Zhao X, Liu L, Soo Y, Pu Y, Pan Y, et al. Prevalence and outcomes of symptomatic intracranial large artery stenoses and occlusions in China. Stroke. 2014;45(3):663-9.

2. van den Wijngaard IR, Holswilder $G$, van Walderveen MA, Algra A, Wermer MJ, Zaidat OO, et al. Brain Behav. 2016;6(11):e00536.

3. Moustafa RR, Moneim AA, Salem HH, Shalash AS, Azmy HA. Intracranial steno-occlusive arterial disease and its associations in Egyptian ischemic stroke patients. Stroke. 2013;44(2):538-41.

4. Cheng L, Jiao L, Gao P, Song G, Chen S, Wang X, et al. Risk factors associated with in-hospital serious adverse events after stenting of severe symptomatic intracranial stenosis. Clin Neurol Neurosurg. 2016;147:59-63.

5. Uehara T., Bang O. Y., Kim J. S., Minematsu K., Sacco R. Risk factors. U. Miami research profile, 2016. 40, 47-57.

6. Amarenco P, Labreuche J, Lavallee P, Touboul P-J. Statins in stroke prevention and carotid atherosclerosis: systematic review and up-to-date meta-analysis. Stroke. 2004;35(12):2902-9.

7. Marcovina S, Packard CJ. Measurement and meaning of apolipoprotein Al and apolipoprotein B plasma levels. J Intern Med. 2006;259(5):437-46.

8. Lima LM, Carvalho M, Sabino A, Mota AP, Fernandes AP, Sousa MO. Apo B/ Apo A-I ratio in central and peripheral arterial diseases. Arq Bras Endocrinol Metab. 2007;51(7):1160-5.

9. Bathala L, Mehndiratta MM, Sharma VK. Cerebrovascular ultrasonography: technique and common pitfalls. Ann Indian Acad Neurol. 2013;16(1):121-7.

10. Sabeti S, Schillinger M, Mlekusch W, Willfort A, Haumer M, Nachtmann T, et al. Quantification of internal carotid artery stenosis with duplex US: 
comparative analysis of different flow velocity criteria. Radiology. 2004 232(2):431-9.

11. Expert Panel on Detection, Evaluation, and Treatment of High Blood Cholesterol in Adults. Executive summary of the third report of the National Cholesterol Education Program (NCEP) expert panel on detection, evaluation, and treatment of high blood cholesterol in adults (adult treatment panel III). JAMA. 2001;285(19):2486-97.

12. Thakur K, Sharma S, Prabhakar S, Gupta P, Anand A. Revisiting the dilution factor as vital parameter for sensitivity of ELISA assay in CSF and plasma. Ann Neurosci. 2015;22(1):37-42.

13. Chan YH. Biostatistics 103: qualitative data - tests of independence. Singap Med J. 2003;44(10):498-503.

14. Chan YH. Biostatistics 202: logistic regression analysis. Singap Med J. 2004; 45(4):149-53.

15. Lei C, Wu B, Liu M, Chen Y. Risk factors and clinical outcomes associated with intracranial and extracranial atherosclerotic stenosis acute ischemic stroke. J Stroke Cerebrovasc Dis. 2014;23(5):1112-7.

16. Li Y, Cai Y, Zhao M, Sun J. Risk factors between intracranial-extracranial atherosclerosis and anterior-posterior circulation stroke in ischaemic stroke. Neurol Res. 2017;39(1):30-5.

17. Triantafyllidi H, Pavlidis G, Trivilou P, Ikonomidis I, Tzortzis S, Xenogiannis I, et al. The association of elevated HDL levels with carotid atherosclerosis in middle-aged women with untreated essential hypertension. Angiology. 2015;66(10):904-10.

18. Kim YD, Choi HY, Jung YH, Nam CM, Yang JH, Cho HJ, et al. Classic risk factors for atherosclerosis are not major determinants for location of extracranial or intracranial cerebral atherosclerosis. Neuroepidemiology. 2009:32(3):201-7.

19. Junyent M, Cofán M, Núñez I, Gilabert R, Zambón D, Ros E. Influence of HDL cholesterol on preclinical carotid atherosclerosis in familial hypercholesterolemia. Arterioscler Thromb Vasc Biol. 2006;26(5):1107-13.

20. Qian Y, Pu Y, Liu L, Wang DZ, Zhao X, Wang C, et al. Low HDL-C level is associated with the development of intracranial artery stenosis: analysis from the Chinese IntraCranial AtheroSclerosis (CICAS) study. PLoS One. 2013; 8(5):e64395.

21. El Zayat S, Fawzy E, Ahmed Zaki M, Zakaria G, Abdel Ghaffar H, Raouf M. A comparison between intracranial and extracranial arteries using neuroimaging in acute ischemic stroke and its relation to risk factors. IJMA. 2020:2(1):320-7.

22. Yang F, Liu L, Xu W, Liu H, Yin Q, Li H, et al. Comparison of carotid and cerebrovascular stenosis between diabetic and nondiabetic patients using digital subtraction angiography. J Stroke Cerebrovasc Dis. 2014; 23(6):1327-31.

23. Ding X, Li C, Yu K, Gao A, Xiao L, Peng F, et al. Different risk factors between intracranial and extracranial atherosclerotic stenosis in Asian population: a systematic review and meta-analysis. Int J Neurosci. 2014;124(11):834-40.

24. Park JH, Hong KS, Lee EJ, Lee J, Kim DE. High levels of apolipoprotein B/AI ratio are associated with intracranial atherosclerotic stenosis. Stroke. 2011; 42(11):3040-6.

25. Park JH, Hong KS, Lee J, Kim YJ, Song P. Deep subcortical infarct burden in relation to apolipoprotein $\mathrm{B} / \mathrm{Al}$ ratio in patients with intracranial atherosclerotic stenosis. Eur J Neurol. 2013;20(4):671-80.

26. Kim DE, Kim JY, Jeong SW, Cho YJ, Park JM, Lee JH, et al. Association between changes in lipid profiles and progression of symptomatic intracranial atherosclerotic stenosis. Stroke. 2012:43(7):1824-30.

27. Wallenfeldt K, Bokemark L, Wikstrand J, Hulthe J, Fagerberg B. Apolipoprotein B/apolipoprotein A-I in relation to the metabolic syndrome and change in carotid artery intima-media thickness during 3 years in middle-aged men. Stroke. 2004:35(10):2248-52.

28. Jadhav UM, Kadam NN. Apolipoproteins: correlation with carotid intimamedia thickness and coronary artery disease. JAPI. 2004:52:370-5.

29. Kaneva AM, Potolitsyna NN, Bojko ER, Odland Jø. Odland, The apolipoprotein B/apolipoprotein A-I ratio as a potential marker of plasma atherogenicity, Disease Markers, vol. 2015, 7 pages.

\section{Publisher's Note}

Springer Nature remains neutral with regard to jurisdictional claims in published maps and institutional affiliations.

\section{Submit your manuscript to a SpringerOpen ${ }^{\circ}$ journal and benefit from:}

- Convenient online submission

- Rigorous peer review

- Open access: articles freely available online

High visibility within the field

- Retaining the copyright to your article

Submit your next manuscript at $\boldsymbol{\text { springeropen.com }}$ 